\title{
The Physiological Effects of IPAD Digital Games on Children with Autism
}

\author{
Najwa Suhaili Md Zin ${ }^{1}$, Nur Zakiah Mohd Saat ${ }^{1, *}$, Sazlina Kamaralzaman ${ }^{2}$ \\ ${ }^{1}$ Programme of Biomedical Sciences, School of Science Diagnostic and Applied Health, Faculty of Health Sciences, Universiti \\ Kebangsaan Malaysia, Malaysia \\ ${ }^{2}$ PERMATA KURNIA, Sentul \\ Kuala Lumpur, Malaysia \\ *Corresponding author's email: nurza [AT] medic.ukm.my
}

\begin{abstract}
----
Background: Previous studies found that the use of an iPad ${ }^{\circledR}$ in intervention programmes benefited the skills of daily living of children with autism. The purpose of the study was to determine the physiological changes in children while playing action and strategy games on an iPad.
\end{abstract}

Methodology: A cross-sectional study was conducted using Powerlab 24/6T, a blood pressure monitor, respiratory belt, and finger pulse transducer. The children were asked to play two types of game. The duration for each game was 10 minutes. The measurement of blood pressure - both systolic and diastolic, heart rate and breathing rate were taken at three consecutive times (before, during and after each game). The inclusion criteria are children aged 7 to 12 years old who have been diagnosed with a mild type of autism (Pervasive developmental disorder). The exclusion criteria were children who had co-morbidities such as epilepsy, migraine, heart, and lung problems, depression, physical disabilities and visual impairments.

Results: Nineteen children with autism participated in this study. The result indicated that the mean systolic and diastolic blood pressures increased before and after playing strategy games and action games. However, compared to pre-play values, the mean heart rate and breathing rate decreased both during and after playing both types of game. Meanwhile, there was significant mean difference for breathing rate for both types of game $(p<0.05)$.

Conclusion: Playing strategy and action games did not affect the measured physiological parameters of children with autism.

Keywords--- systolic;diastolic;heart rate;breathing rate

\section{INTRODUCTION}

The prevalence of autism spectrum disorder or ASD is on the rise globally. ASD is a neurological developmental disorder that occur in children and lifelong condition characterized by impairments in social and communication skills, and stereotyped behaviors and restricted interests. Recent reviews have concluded that current best estimates for the prevalence of ASD lie between 0.7 and $1.0 \%{ }^{1}$. However, some studies have yielded estimates over 2 $\%$ Pelly et al. ${ }^{2}$ and even as high as $2.64 \%^{3}$ of ASD. Causes of ASD are still unknown but several studies had pointed out that genetics and environmental factors are key etiologies that may have caused ASD.

Obsession, incline to routine activities and rigid towards changes are among common characteristics of individuals with autism ${ }^{4}$. Due to these issues, some children with ASD are drawn towards digital devices such as iPad® For this reason, many researches had resorted to using iPad as medium for interventions ${ }^{5}$. There were immediate increase of apps development in area of intervention for ASD, which were used as complement to the conventional early intervention programmes ${ }^{6}$. The touch-screened surface, portability, easy access to information and development of teaching materials as well as social media platforms to assist individuals with social communication issues, had made iPad, a preferable medium for intervention ${ }^{6}$. Majority of the App-based intervention developed were aimed at teaching academic, communication, leisure, activity transition and employment skills ${ }^{7}$. 
In many instances, iPad games were used as leisure activity for children with autism. However, using games can have a positive and negative effects on players. A study conducted among psychology students by previous researcher ${ }^{3}$ has shown that men played violent video games more than women. A further study found that male students became involved in crime and did not do well academically ${ }^{8}$. As a result, it is proven that violent video games have negative impacts on these students, which tend to involve real-life aggression and crime. However, Durkin and Barber ${ }^{9}$ strongly agree that video games have a positive impact on the users. They experimented on three groups of psychology students which they divided according to the amount of time they spent playing games into three groups: none, low and high. The 'high' participants reported having good relationships with friends and being committed to school and academic study. On the contrary, the participants who did not play games reported as disobedient. Hence, other researcher stated that video games are something that young people are used to and are unlikely to affect them mentally ${ }^{9}$.

Previous physiological and psychological studies yielded interesting finding regarding the use of iPads. For example a study by Saat et al. $^{11}$ involved university students using iPads® measures psychological parameters before and after playing strategic and action games. The results indicated that there were significant differences in breathing rate between strategy and action games $(\mathrm{p}<0.05)$. The mean breathing rate was slightly higher during action games compared with strategy games. Another interesting finding was the significant mean difference in heart rate between male and female students. The heart rate of female students was higher on average compared to male students when playing strategy games.

In sight with the increase of usage iPads as therapeutic medium of intervention, there is yet any study on the impact of using IPad® apps on the physiological responses of children with autism. Therefore, the purpose of this study was to measure the relationship between psychophysiological responses for children with autism when they are playing games using an $\mathrm{iPad} \circledast$.

\section{METHODOLOGY}

\section{Research Design}

A cross-sectional study was done using Powerlab 24/6T, a blood pressure monitor, respiratory belt, and finger pulse transducer. 19 children with autism participated in this study. The inclusion criteria are children between 7 to 14 years old who have been diagnosed with a mild type of autism (Pervasive developmental disorder). The rejection criteria included children with other health problems such as epilepsy, migraine, heart and lung problems; children with depression; children living with disability and children with visual impairments.

In this study, the researcher has received approval from the UKM ethical committees. The researcher also asked permission from the parents of the children with autism to participate in this research. In addition, a pilot study was conducted on children with and without autism. Firstly, once the child arrived at the experiment room the researcher allowed him/her to rest for 5 minutes whilst building rapport to enhance communication as much as possible. Then, the researcher measured the blood pressure, breathing rate, pulse rate, and heart rate of the child. Then, the first game was played and breathing rate, pulse rate, and heart rate measured while the child was playing the game. After the first game ended, the researcher removed the iPad ${ }^{\circledR}$ from the child and measured the four readings. The child was given 10 minutes to rest. After having 10 minutes rest, the researcher returned the iPad® to the child for the second game. Again, a finger pulse transducer, respiratory belt transducer and blood pressure monitor was used. The researcher measured the blood pressure, breathing rate, pulse rate, and heart rate of the child while s/he played the game. After finishing the second game, the researcher asked the child to sit still to take other measurements. In this study, two types of game were chosen: an academic type and a strategy type. The academic type was Animal Jigsaw Puzzle and the strategy type was Subway Surfers.

\section{Chart 1: The procedure for the study}

For the children with autism, the researcher adapted the social story method by Gray ${ }^{12}$ Social story could enhance the communication and social skills among the autistic children by guiding and supporting the children's reactions in society. Social story is needed to introduce new routines or situations to autistic children since they find it very hard to change something they are used to. According to Hasnah et al. ${ }^{13}$, through this social story, the children with autism may have expectations of a new situation whilst wondering what is going to happen and how to react to the events appropriately. 


\section{RESULTS}

Tables 1 and 2 show the descriptive results of the subjects. For autistic children, most are male and aged more than 11 years old.

Table 1: Descriptive results for children with autism $(n=19)$

\begin{tabular}{r|rrr}
\hline \multirow{3}{*}{ Gender } & & n & \% \\
\cline { 2 - 4 } Age & Male & 17 & $\mathbf{8 9 . 5}$ \\
& Female & 2 & 10.5 \\
& $<11$ & 5 & 26.3 \\
& $\geq 11$ & 14 & 73.7 \\
\hline
\end{tabular}

Table 2: The descriptive results of physiology measurement for strategic games (Game 1)

\begin{tabular}{cccccccc}
\hline Variables & $\mathrm{N}$ & \multicolumn{2}{c}{ Before } & \multicolumn{2}{c}{ During } & \multicolumn{2}{c}{ After } \\
& & mean & SD & mean & SD & mean & SD \\
\hline Systolic & 19 & 101.8 & 19.2 & - & - & 101.2 & 14.03 \\
Diastolic & 19 & 71.9 & 17.5 & - & - & 67.6 & 12.7 \\
Heart Rate & 19 & 93.1 & 19.8 & 93.2 & 30.9 & 95.4 & 13.2 \\
Breathing Rate & 19 & 27.0 & 5.4 & 27.3 & 3.80 & 26.2 & 6.4 \\
\hline
\end{tabular}

According to Table 3, there are slight changes of systolic blood pressure before and after playing Game 1 . The mean diastolic blood pressure (DBP) decreases after playing Game 1. For the heart rate, the mean heart rate was higher during playing Game 1. Furthermore, for the mean breathing rate after playing the game is higher compared to before and during game play. The pulse rate is higher after playing Game 1 compared to before playing Game 1. Furthermore, the systolic blood pressure reading is decreased before playing Game 2. The reading for the diastolic blood pressure also shows an increase after the playing of Game 2. For the heart rate, the mean heart rate was higher during playing Game 2. Furthermore, for the breathing rate the mean after playing game for strategy games is higher compared to before and during playing the game. The pulse rate is higher after playing strategy game compared to before playing action game.

Table 3: The descriptive results of action games(Game 2)

\begin{tabular}{cccccccc}
\hline Variables & $\mathrm{N}$ & \multicolumn{2}{c}{ Before } & \multicolumn{2}{c}{ During } & \multicolumn{2}{c}{ After } \\
& & mean & SD & mean & SD & mean & SD \\
\hline Systolic & 19 & 97.8 & 17.8 & - & - & 99.5 & 15.3 \\
Diastolic & 19 & 58.9 & 14.9 & - & - & 62.9 & 19.2 \\
Heart Rate & 19 & 94.7 & 12.2 & 87.5 & 22.9 & 94.6 & 17.2 \\
Breathing Rate & 19 & 24.8 & 4.8 & 28.7 & 4.9 & 24.8 & 5.3 \\
\hline
\end{tabular}

In Table 4, we want to determine the mean difference between before and after playing games 1 and 2 for systolic and diastolic blood pressure. Meanwhile, in this study, we want to compare the heart rate and breathing rate for three continuous times. The results indicated that the mean systolic after playing Game 1 is higher compared to Game 2 . There was no significant mean difference between Game 1 and Game 2 for systolic blood pressure. $(\mathrm{F}=0.039, \mathrm{p}=$ 0.844). In addition, the results conveyed the mean diastolic after playing Game 1 is quite similar to that after playing Game 2. There was no significant difference between Game 1 and Game 2 for DBP readings. $(F=0.201, p=0.249)$.

Furthermore, results in Table 4 also showed the mean difference between heart rate readings in three conditions. It can be seen that the readings before and after are slightly different, whereas during playing games 1 and 2 , the readings are quite high. The results show there was no significant difference between games 1 and 2 for heart reading. ( $F=0.613$, $\mathrm{p}=0.508$ ). Meanwhile, the readings for breathing rate before and after in Game 1 and Game 2 show a significant mean difference with $\mathrm{F}=3.280, \mathrm{p}=0.043$. 
Table 4: Comparison between two different types of game

\begin{tabular}{|c|c|c|c|c|c|c|c|c|c|}
\hline & & $\begin{array}{l}\text { Before } \\
\text { mean }\end{array}$ & SD & $\begin{array}{l}\text { During } \\
\text { mean }\end{array}$ & SD & $\begin{array}{l}\text { After } \\
\text { mean }\end{array}$ & SD & $\mathrm{F}$ & $\mathrm{p}$ \\
\hline \multirow[t]{2}{*}{ Systolic } & $\begin{array}{c}\text { Game } \\
1\end{array}$ & 101.8 & 19.2 & - & - & 101.2 & 14.03 & 0.039 & 0.844* \\
\hline & $\begin{array}{c}\text { Game } \\
2\end{array}$ & 97.8 & 17.9 & - & - & 99.5 & 15.3 & & \\
\hline \multirow[t]{2}{*}{ Diastolic } & $\begin{array}{c}\text { Game } \\
1\end{array}$ & 73.8 & 17.5 & - & - & 67.5 & 12.7 & 1.376 & 0.249 \\
\hline & $\begin{array}{c}\text { Game } \\
2\end{array}$ & 58.8 & 14.9 & - & - & 65.2 & 13.05 & & \\
\hline \multirow[t]{2}{*}{ Heart Rate } & $\begin{array}{c}\text { Game } \\
1\end{array}$ & 93.1 & 19.8 & 93.1 & 30.8 & 95.4 & 13.15 & 0.613 & 0.508 \\
\hline & $\begin{array}{c}\text { Game } \\
2\end{array}$ & 94.7 & 12.2 & 87.5 & 22.9 & 94.6 & 17.1 & & \\
\hline \multirow{2}{*}{$\begin{array}{l}\text { Breathing } \\
\text { Rate }\end{array}$} & Game & 27.0 & 5.37 & 27.1 & 3.77 & 26.2 & 6.4 & 3.280 & $0.043 *$ \\
\hline & $\begin{array}{c}1 \\
\text { Game } \\
2\end{array}$ & 24.7 & 4.79 & 28.8 & 4.95 & 24.8 & 5.29 & & \\
\hline
\end{tabular}

\section{DISCUSSION}

Digital games can be used as one of the psychotherapeutic methods for young people and children, especially for those with mental healthcare needs ${ }^{14,15}$. According to Lenhart et al. ${ }^{16}, 72.0 \%$ of their subjects chose puzzle genre games and only $67 \%$ chose to play action genre games. Moreover, computers are still the most popular medium for digital gaming despite the availability of other devices like the iPad® or mobile phones. This was supported by Nacke \& Lindley ${ }^{17}$ who showed that $96 \%$ of the players favored their personal computer when playing games. Studies by Payne et al. ${ }^{18}$ and Johnson et al. ${ }^{19}$ indicated that the video presented on the Ipod Touch improves the skills of daily living for students with learning disabilities ${ }^{20,21}$. Meanwhile, a study by Palmen et al. ${ }^{20}$ indicated that using a personal digital assistant (PDA) increased the capabilities of daily routines among those with autism. This showed that the use of technologies does improve the routine activities for children with autism ${ }^{21}$. In this study, blood pressure, heart rate and breathing rate are within the normal range for both game types. Therefore, the researcher can suggest these two types of games to the parents of children with autism as they had little influence on physiological measurements. For children with autism who love to play digital games during leisure time, both types of game are therefore acceptable.

In this study, the results showed that there was a significant difference in systolic blood pressure before and after playing both strategy and action games. However, there was no significant mean difference for diastolic blood pressure under the same conditions. This is parallel with the study by Saat et al. ${ }^{11}$ which indicated that there was a mean difference SBP before and after playing strategy games ${ }^{22}$. This was supported by Markovitz et al. ${ }^{21}$ who showed a significant difference in systolic blood pressure with gender for both game types. Other studies by Drachen et al. ${ }^{20}$ and Segal \& Diatz ${ }^{23}$ indicated that different genres of games have different psychophysiological responses. Meanwhile, a study among children aged 7 to 10 years old by Wang \& Perry ${ }^{24}$ indicated that there were increases in heart rate and systolic and diastolic blood pressure before and after playing video games.

Heart rate measured during action games and strategy games showed an increment but with no significant difference between both games. This result was parallel with another study by Mandryk et al. ${ }^{25}$ which showed no significant correlation between heart rate and players' subjective measures such as stress. Another study by Segal \& Dietz $^{23}$ indicated that playing video games does increase the heart rate, SBP, and DBP among adults aged from 25 to 36 years old. Another study by Gwinup et $a l .^{27}$ indicated there was an increase in heart rate among young men comparing before and after playing video games. Furthermore, another study by Drachen et al. ${ }^{22}$ found out that an increasing heart rate showed that the players were in a stressful situation. This is because during gameplay there are increases in arousal and a strong emotional response as investigated by Ledunois et al. ${ }^{27}$ and Hebert et al. ${ }^{30}$.

This study shows that measurements of breathing rate increased significantly in action games rather than during strategy gameplay. The rise in breathing rate was thought to be caused by the emotional arousal, whereas the decreases in the breathing rate measurements were said to happen in a relaxed environment as investigated by Stern $e t$ al. ${ }^{29}$. Besides that, the study by Mandryk \& Inkpen ${ }^{30}$ showed there is no significant difference in heart rate and breathing rate between 
two different gameplays and it might happened according to the types of games chosen. Another study by Wang \& Perry ${ }^{24}$ among boys aged 7 to 10 years old indicated that playing does increase the HR, SBP, and DBP significantly.

The results from this study support the emerging concern of practitioners and parents on the effect of playing digital games on children with autism. Previous studies used the iPad ${ }^{\circledR}$ as a tool to treat a language delay investigated by King et $a l .{ }^{32}$ and interventions investigated by Lee et $a l .{ }^{33}$ and others. This study shows that the systolic blood pressure, diastolic blood pressure, heart rate and breathing rate were within the normal range. Therefore there were no negative effects of playing action and strategy games. However, there was an increment of SBP, DBP, HR, and BR during action gaming. This study has shown that there was no significant mean difference in the physiological measurements between strategy and action game indicating that, even though children with autism play action games, it does not influence their blood pressure as they have used, and like to play, digital games. When the events have become habitual or frequent, it does not influence their blood pressure, pulse rate and breathing rate. This shows that using the Ipad as a tool for teaching is safe and will not influence their physiological readings.

\section{CONCLUSION}

In conclusion, physiological measures such as systolic blood pressure and breathing rate, have no association with the types of gameplay using the iPad®. The results in this study show that action and strategy games can be used as a therapeutic method as there were only slight differences in the psychophysiological measures. All of the changes in the psychophysiological measures were within the normal range for autistic children. Therefore, the usage of iPad® games may alter an individual's physiological response in a preferable manner as these games enhanced the cognition of players from time to time. These $\mathrm{iPad} \circledast$ games may also be used as a therapeutic tool during occupational therapy or other healthcare fields used for cognitive rehabilitation.

\section{ACKNOWLEDGEMENT}

We wished to thank Universiti Kebangsaan Malaysia and Ministry of Education Malaysia for research grant FRGS/2/2013/SKK10/UKM/03/1.

\section{REFERENCES}

1. Hill, A. P., Zuckerman, K., \& Fombonne, E. (2014). Epidemiology of autism spectrum disorders. In F. R. Volkmar, S. J. Rogers, R. Paul, \& K. A. Pelphrey (Eds.), Handbook of autism and pervasive developmental disorders. Diagnosis, development, and brain mechanisms (4th ed., Vol. 1, pp. 57-96). New York: Wiley.

2. Pelly, L., Vardy, C., Fernandez, B., Newhook, L. A., \& Chafe, R. (2015). Incidence and cohort prevalence for autism spectrum disorders in the Avalon Peninsula, Newfoundland and Labrador. CMAJ open, 3(3), E276-E280.

3. Kim, Y. S., Leventhal, B. L., Koh, Y. J., Fombonne, E., Laska, E., Lim, E. C., et al. (2011). Prevalence of autism spectrum disorder in a total population sample. American Journal of Psychiatry, 168(9), 904-912.

4. American Psychiatric Assocation. DSM-5. Washington, DC: American Psychiatric Association; 2013

5. Fletcher-Watson S, Petrou A, Scott-Barrett J, Dicks P, Graham C, O’Hare A, Pain H, McConachie H: A trial of an $\mathrm{iPad} \circledast$ intervention targeting social communication skills in children with autism. Autism. 2015:1362361315605624.

6. Alliano A, Herriger K, Koutsoftas AD, Bartolotta TE. A review of 21 iPad applications for augmentative and alternative communication purposes. SIG 12 Perspect Augment Altern Commun. 2012;21(2):60-71.

7. Kagohara DM, van der Meer L, Ramdoss S, O’Reilly MF, Lancioni GE, Davis TN, Rispoli M, Lang R, Marschik PB, Sutherland D. Using iPods ${ }^{\circledR}$ and iPads ${ }^{\circledR}$ in teaching programs for individuals with developmental disabilities: a systematic review. Res Dev Disabil. 2013;34(1):147-56.

8. Anderson, C. A., \& Dill, K. E. (2000). Video games and aggressive thoughts, feelings, and behavior in the laboratory and in life. Journal of personality and social psychology, 78(4), 772.

9. Durkin, K., \& Barber, B. (2002). Not so doomed: Computer game play and positive adolescent development. Journal of applied developmental psychology, 23(4), 373-392.

10. Fallon, S. (2014). A Conjoint Analysis of Reader Preference for the Layout of Tablet Editions of Magazines.

11. Saat NZM, Sazlina Kamaralzaman, Nurul Asyiqah Aspen, Nina Atiqah Mat Supri, Nur Rafidah Mohamed.2014. The Association between Physiopsychological Effects and the Types of Games among University Students. Asian Journal of Applied Sciences 2(3):393-400

12. Gray, C. A., \& Garand, J. D. (1993). Social stories: Improving responses of students with autism with accurate social information. Focus on Autistic Behavior.

13. Hasnah Toran, Salmiah Bujang \& Fadliana Chiri. Siri Pendidikan Autisme: Pengajaran Berstruktur. Penerbit UKM 
14. Ceranoglu, T. A. (2010). Video games in psychotherapy. Review of General Psychology, 14(2), 141.

15. Griffiths, M. (1999). Violent video games and aggression: A review of the literature. Aggression and violent behavior, 4(2), 203-212.

16. Lenhart, A., Maddenn, M., \& Hitlin, P. (2005). Teens and technology: Youth are leading the transition to a fully wired and mobile nation.

17. Nacke, L., \& Lindley, C. A. (2008, November). Flow and immersion in first-person shooters: measuring the player's gameplay experience. InProceedings of the 2008 Conference on Future Play: Research, Play, Share(pp. 81-88). ACM.

18. Payne, D., Cannella-Malone, H. I., Tullis, C. A., \& Sabielny, L. M. (2012). The effects of self-directed video prompting with two students with intellectual and developmental disabilities. Journal of Developmental and Physical Disabilities, 24(6), 617-634.

19. Johnson, J. W., Blood, E., Freeman, A., \& Simmons, K. (2013). Evaluating the effectiveness of teacherimplemented video prompting on an iPod Touch to teach food-preparation skills to high school students with autism spectrum disorders. Focus on Autism and Other Developmental Disabilities, 1088357613476344

20. Palmen, A., Didden, R., \& Verhoeven, L. (2012). A personal digital assistant for improving independent transitioning in adolescents with high-functioning autism spectrum disorder. Developmental neurorehabilitation, 15(6), 401-413.

21. Markovitz, J. H., Raczynski, J. M., Wallace, D., Chettur, V., \& Chesney, M. A. (1998). Cardiovascular reactivity to video game predicts subsequent blood pressure increases in young men: The CARDIA study. Psychosomatic medicine, 60(2), 186-191.

22. Drachen, A., Nacke, L. E., Yannakakis, G., \& Pedersen, A. L. (2010, July). Correlation between heart rate, electrodermal activity and player experience in first-person shooter games. In Proceedings of the 5th ACM SIGGRAPH Symposium on Video Games (pp. 49-54). ACM.

23. Segal, K. R., \& Dietz, W. H. (1991). Physiologic responses to playing a video game. American Journal of Diseases of Children, 145(9), 1034-1036.

24. Wang, X., \& Perry, A. C. (2006). Metabolic and physiologic responses to video game play in 7-to 10-year-old boys. Archives of Pediatrics \& adolescent medicine, 160(4), 411-415.

25. Mandryk, R. L., Inkpen, K. M., \& Calvert, T. W. (2006). Using psychophysiological techniques to measure user experience with entertainment technologies. Behaviour \& information technology, 25(2), 141-158.

26. Gwinup, G., Haw, T., \& Elias, A. (1983). Cardiovascular changes in video-game players. Cause for concern?. Postgraduate medicine, 74(6), 245-248.

27. Denot-Ledunois S, Vardon G, Perruchet P, Gallego J. The effect of attentional load on the breathing pattern in children. Int J Psychophysiol. 1998;29: 13-21

28. Hébert, S., Béland, R., Dionne-Fournelle, O., Crête, M., \& Lupien, S. J. (2005). Physiological stress response to video-game playing: the contribution of built-in music. Life sciences, 76(20), 2371-2380.

29. Stern, Y. (2012). Cognitive reserve in ageing and Alzheimer's disease. The Lancet Neurology, 11(11), 10061012.

30. Mandryk, R. L., \& Inkpen, K. M. (2004, November). Physiological indicators for the evaluation of co-located collaborative play. In Proceedings of the 2004 ACM conference on Computer supported cooperative work (pp. 102-111). ACM.

31. Hébert, S., Béland, R., Dionne-Fournelle, O., Crête, M., \& Lupien, S. J. (2005). Physiological stress response to video-game playing: the contribution of built-in music. Life sciences, 76(20), 2371-2380.

32. King, D., Delfabbro, P., \& Griffiths, M. (2010). Video game structural characteristics: A new psychological taxonomy. International Journal of Mental Health and Addiction, 8(1), 90-106.

33. Lee, S. (2012). Project Injini: Developing cognitive training games for children with special needs. GAMES FOR HEALTH: Research, Development, and Clinical Applications, 1(1), 69-73. 